\title{
TRIBUNAL CONSTITUCIONAL. ACCIÓN DE INAPLICABILIDAD POR INCONSTITUCIONALIDAD DEL INCISO FINAL DEL ARTÍCULO 501 DEL CÓDIGO DEL TRABAJO. RECHAZADA. ROL 1514-09-INA.
}

\begin{abstract}
RESUMEN: La Iltma. Corte de Apelaciones de Talca planteó que el inciso final del artículo 501 del Código del Trabajo, en tanto exime de consignar el análisis de la prueba rendida; los hechos que se estime probados y el razonamiento que conduce a esa estimación en la sentencia definitiva del procedimiento monitorio laboral, impediría a la parte perdidosa conocer cuál es la razón por la que se rechazó su pretensión y, por ende, ejercer su derecho a defensa jurídica a través de los recursos que contempla el ordenamiento vigente, con lo cual infringiría el artículo 19 N.03 de la Constitución Política de la República. El Tribunal Constitucional no hace lugar a dicho requerimiento, en primer término, bajo el argumento que la exclusión del recurso de nulidad por infracción manifiesta de las normas sobre apreciación de la prueba como consecuencia del precepto cuestionado no priva a los interesados absolutamente de dicho medio de impugnación, ya que deja subsistente la causal genérica del art. 477 del Código del Trabajo.

En segundo lugar, hace presente que lo que se ventila en la acción de inaplicabilidad no es el ajuste o contradicción en abstracto entre dos normas de diverso rango, sino los efectos que, en un caso específico, produce la aplicación de un precepto legal. Dado que la sentencia definitiva dictada en el juicio en que se plantea el requerimiento sí cumplió, aunque no le eran exigibles, con los requisitos que el inciso final del artículo 501 autorizaba omitir, no se da en el caso sub lite una aplicación inconstitucional de la norma cuestionada.
\end{abstract}

Santiago, doce de octubre de dos mil diez.

\section{VISTOS}

Con fecha 19 de octubre de 2009, ingresó a esta Magistratura el Oficio $\mathrm{N}^{\circ} 132$, fechado el día 16 del mismo mes y año, mediante el cual el señor Presidente Subrogante de la Corte de Apelaciones de Talca expone: "En la Causa Rol Corte N $55-2009$ Reforma Laboral y Rit No M-37-2009 del Juzgado de Letras, Familia y del Trabajo de San Javier, caratulada "Valdés Cáceres Víctor Hernán con Bravo González José Humberto" se ha dispuesto como medida para mejor acierto del fallo, remitir a US. Excma. estos antecedentes a fin de que se sirva resolver acerca de la inaplicabilidad por inconstitucionalidad del inciso final del artículo 501 del Código del Trabajo, en relación con lo dispuesto en el artículo 478 letra b) del mismo cuerpo legal y al artículo $19 \mathrm{~N}^{\circ} 3$ de la Constitución Política de la República".

En cumplimiento de lo resuelto por la Segunda Sala de esta Magistratura el 27 de octubre de 2009 -fojas 72-, el requerimiento deducido por la mencionada Corte de Apelaciones fue complementado mediante oficios $\mathrm{N}^{\circ} \mathrm{s} 3645$ y 3682, ingresados a este Tribunal Constitucional los días 2 y 5 de noviembre de 2009. En ambos se remite la resolución dictada en la gestión sub lite por la Tercera Sala de esa Corte, el 28 de octubre de 2009, y que, en síntesis, establece que esta acción se formuló en razón de que, al tratar el contenido de la sentencia dictada en un procedimiento monitorio, el artículo 501 del Código del Trabajo, impugnado, excluye expresamente el requisito previsto en el numeral $4^{\circ}$ del artículo 459 del mismo texto legal, que, a su vez, dispone que la sentencia definitiva debe contener, entre 
otros, el análisis de toda la prueba rendida, los hechos que se estimen probados y el razonamiento que conduce a esa estimación.

La exclusión del referido requisito, a juicio de la Corte de Apelaciones requirente, produciría como efecto las siguientes situaciones de interés jurídico constirucional:

La primera, relacionada con la procedencia del recurso de nulidad fundado en el artículo 478, letra b), del Código del Trabajo, cuando se trate de una sentencia dictada en un procedimiento monitorio, y la segunda dice relación con la duda que surge respecto de si el inciso final del artículo 501 del referido Código se ajusta o no a la garantía asegurada en el artículo $19 \mathrm{~N}^{\circ} 3^{\circ}$ de la Carta Fundamental. La Corte expresa que la exclusión del requisito de la sentencia que permite la norma cuestionada impediría a la parte que no obtuvo en la misma conocer cuál es la razón por la que se rechazó su pretensión y, por ende, ejercer su derecho a defensa jurídica a través de los recursos que contempla el ordenamiento vigente.

Consta a fojas 78 de autos que la Segunda Sala de este Tribunal declaró admisible la acción deducida por resolución fechada el 10 de noviembre de 2009. Pasados los autos al Pleno, se dispuso comunicar el requerimiento a los órganos constitucionales interesados y a las partes de la causa judicial en la que aquel incide, ninguno de los cuales ha formulado observaciones a su respecto.

Finalmente, consta a fojas 101 de los autos que el Tribunal tuvo presente que a los efectos de este proceso constitucional los abogados de la Unidad de Coordinación de la Defensa Laboral del Ministerio de Justicia, Ariel Rossel Zúniga y María Patricia Donoso Gomien, han asumido el patrocinio y la representación judicial del demandante del juicio sub lite, señor Víctor Hernán Valdés Cáceres. Habiéndose traído los autos en relación, el día 26 de agosto de dos mil diez se procedió a la vista de la causa, oyéndose los alegatos del abogado Ariel Rossel Zúñiga, por el señor Víctor Hernán Valdés Cáceres.

\section{CONSIDERANDO}

Primero: Que la Constitución Política de la República, en el $N^{\circ} 6^{\circ}$ del inciso primero de su artículo 93, confiere a este Tribunal Constitucional la facultad de resolver la inaplicabilidad de un precepto legal cuya aplicación en cualquier gestión que se siga ante un tribunal ordinario o especial, resulte contraria a la Constitución, siempre que la acción sea planteada por cualquiera de las partes o por el juez que conoce del asunto y una de las salas del Tribunal haya declarado la admisibilidad de la cuestión, conforme lo dispone el inciso undécimo de la misma norma constitucional;

SEGUNDO: Que, según se ha expuesto antes, el requerimiento se funda en la eventual “inaplicabilidad por inconstitucionalidad del inciso final del artículo 501 del Código del Trabajo, en relación con lo dispuesto en el artículo 478, letra b), del mismo cuerpo legal y al artículo $19 \mathrm{~N}^{\circ} 3$ de la Constitución Política de la República”, debiendo entenderse que la posible vulneración recae sobre la garantía del debido proceso;

TERCERO: Que el tenor del artículo 501, inciso final, del Código del Trabajo es el siguiente: "El juez deberá dictar sentencia al término de la audiencia, la que deberá contener las menciones señaladas en los números 1, 2, 5, 6 y 7 del artículo 459"; en tanto que el 
texto del artículo 478 , letra b), de dicho cuerpo legal establece que: "El recurso de nulidad procederá, además, cuando la sentencia haya sido pronunciada con infracción manifiesta de las normas sobre la apreciación de la prueba conforme a las reglas de la sana crítica";

CUARTO: Que la primera duda que se ha suscitado en el tribunal requirente versa sobre la procedencia del recurso de nulidad fundado en el artículo 478 , letra b), del citado Código, cuando se trata de una sentencia dictada en procedimiento monitorio.

Dicha cuestión debe descartarse tanto porque no incide, por su naturaleza, en un asunto de constitucionalidad en la aplicación de la norma, cuanto porque la exclusión del recurso de nulidad por infracción manifiesta de las normas sobre apreciación de la prueba -en el procedimiento monitorio- no priva a los interesados absolutamente de dicho medio de impugnación. Este es procedente, por regla general, cuando se hubieren transgredido sustancialmente derechos o garantías constitucionales o la sentencia se hubiere dictado con infracción de ley que hubiere influido sustancialmente en lo dispositivo del fallo (artículo 477 del Código del Trabajo);

QUINTO: Que el segundo capítulo del requerimiento deriva de la eventual violación de la garantía del debido proceso por la omisión del análisis de la prueba rendida, de los hechos que se estimen probados y del razonamiento que conduce a esa estimación, que impediría a la parte que no obtuvo conocer las razones por las cuales se rechazan sus pretensiones y le imposibilitaría interponer de manera fundada los recursos que contempla la legislación, atropellándose el derecho a defensa jurídica;

SEXTO: Que esta Magistratura, conociendo de un requerimiento sobre los efectos inconstitucionales del artículo 768, inciso antepenúltimo, del Código de Procedimiento Civil, que prohíbe instar por la anulación de una sentencia definitiva que desconoce el deber de fundar las decisiones, estableció que "puede concluirse que la motivación de la sentencia es connatural a la jurisdicción y fundamento indispensable para su ejercicio. Es inherente al derecho a la acción y, por ende, a la concreción de la tutela judicial efectiva, elementos propios de las garantías de un procedimiento racional y justo, cuya ausencia o limitación vulnera la exigencia constitucional y autoriza declarar la inaplicabilidad del precepto objetado" (considerando decimoquinto, sentencia Rol 1373-09-INA);

SÉPTIMO: Que dicha doctrina se estableció a propósito de la inaplicación de un precepto que excluía el recurso de casación en la forma, en materia civil, en juicios regidos por leyes especiales. El ámbito en que incide -derecho civil-es ciertamente muy diverso del que se regula en el caso ahora en examen, relativo al procedimiento monitorio en juicios laborales de mínima cuantía, signado por caracteres muy marcados de oralidad, concentración e inmediatez;

OCTAVO: Que, sin perjuicio de lo anotado, lo que se ventila en este proceso constitucional no es el ajuste o contradicción entre dos normas de diverso rango, cotejadas en abstracto, sino el análisis y decisión de los efectos que, en un caso específico donde se juzga una determinada relación jurídico-procesal, produce la aplicación de un precepto legal.

La inconstitucionalidad que sirve de fundamento a la acción no se apoya, entonces, en un vicio de la norma, sino de los efectos de su aplicación: una disposición legal puede conformarse a la Constitución y, no obstante ello, en su aplicación producir efectos contrarios a la misma; de otro lado, un precepto puede contradecir la norma constitucional y -por 
falta de aplicación a la relación jurídica constitutiva de la litis- no producir efectos que pugnen con aquella;

NOVENO: Que, para los fines anteriores, cabe considerar que el acta de audiencia única de conciliación, contestación y prueba de procedimiento monitorio, que corre a fojas 40 y siguientes del expediente, incluye la sentencia definitiva, de cuyo examen se infiere que la misma -aunque no fuera exigible-cumple con los requisitos que el artículo 459 hace aplicable al fallo en el procedimiento común laboral y contiene, entre otras menciones, una síntesis de los hechos y de las alegaciones de las partes y el análisis de toda la prueba rendida, los hechos que estima probados y el razonamiento que conduce a esta estimación;

DÉCIMO: Que, en consecuencia, el precepto tachado -inciso final del artículo 501 del Código del Trabajo- no ha tenido aplicación en el caso sub lite, pues las menciones que autoriza omitir (las de los números 3 y 4 del artículo 459 del Código del Trabajo) -y cuya omisión justificaría el reproche constitucional- han sido consignadas en la sentencia definitiva. No se da, entonces, una aplicación inconstitucional de la norma, en la forma que sostiene el tribunal requirente, pues ella simplemente no ha recibido aplicación alguna;

UNDÉCIMO: Que, en relación con lo expuesto, es preciso señalar que la inaplicabilidad del precepto impugnado (que contiene una regla singular para el procedimiento monitorio) solo provocaría la aplicación de la norma supletoria ya indicada -artículo 459 del Código del Trabajo, ubicado en el párrafo $3^{\circ}$, sobre procedimiento de aplicación general-, la que, como se ha dicho, ha sido observada por el fallo; deducido.

DUODÉCIMO: Que, por las motivaciones referidas, no se hará lugar al requerimiento

Y VISTO lo dispuesto en los artículos $19, \mathrm{~N}^{\circ} 3,93$, inciso primero, No $6^{\circ}$, e inciso undécimo, de la Constitución Política de la República, así como en las disposiciones pertinentes de la Ley No 17.997, Orgánica Constitucional del Tribunal Constitucional, cuyo texto refundido, coordinado y sistematizado fue fijado por el Decreto con Fuerza de Ley No 5, de 2010, del Ministerio Secretaría General de la Presidencia,

\section{SE RESUELVE}

Que no se hace lugar al requerimiento interpuesto. Los Ministros señores Marcelo Venegas Palacios (Presidente), Raúl Bertelsen Repetto e Iván Aróstica Maldonado previenen que concurren al fallo y a sus fundamentos, en especial los que sustentan que el precepto cuestionado no tendrá aplicación en la gestión sub lite, pero no comparten su considerando OCTAVO, por estimar que, no obstante las peculiaridades propias del control concreto que caracterizan la actual acción de inaplicabilidad, que demandan examinar la constitucionalidad de la aplicación del precepto impugnado a cada caso específico, siempre será inconstitucional la aplicación, en cualquier gestión judicial, de un precepto legal que en sí mismo, examinado en abstracto, es contrario a la Constitución.

Los Ministros señores Francisco Fernández Fredes y Carlos Carmona Santander previenen, teniendo en cuenta, para rechazar el presente requerimiento, lo siguiente: 
1. Que si bien el artículo 501, inciso tercero, del Código del Trabajo parece eximir al juez que dicta sentencia en un procedimiento monitorio de la obligación señalada en los números 3 y 4 del artículo 459 , que regula el contenido de toda sentencia, en el sentido de contener "una síntesis de los hechos y de las alegaciones de las partes" y "el análisis de toda la prueba rendida, los hechos que estime probados y el razonamiento que conduce a esta estimación", en atención a la naturaleza de este procedimiento (verbal, concentrado, con obligación de dictar sentencia al término de la audiencia), otros numerales del mismo artículo 459 , de los que no se releva al juez, permiten sostener que debe existir algún tipo de razonamiento destinado a examinar los antecedentes que constan en el proceso y su valoración.

2. Que, en efecto, la sentencia definitiva debe contener, de acuerdo al mencionado artículo 459, por una parte, "las consideraciones jurídicas y los principios de derecho o de equidad en que el fallo se funda" ( $\left.\mathrm{N}^{\circ} 5\right)$; por la otra, debe contener "la resolución de las cuestiones sometidas a la decisión del Tribunal".

3. Que la existencia de estos numerales debe interpretarse armónicamente con la excepción del inciso tercero del artículo 501. Esa es la única manera de salvar la exigencia constitucional de que las sentencias deben fundarse. Dicho mandato emana del artículo $19 \mathrm{~N}^{\circ} 3$, que exige que toda sentencia "debe fundarse en un proceso previo", y de la tutela judicial efectiva que consagra dicho precepto. También fluye del artículo $8^{\circ}$ de la Constitución, que establece que los fundamentos de los actos o resoluciones de los órganos del Estado, incluidos los tribunales, son públicos. Asimismo, del hecho que Chile es una república democrática (artículo $4^{\circ}$ ), lo que obliga a que los órganos fundamenten sus decisiones para justificarse ante la ciudadanía y evitar todo abuso.

4. Que, como se ha señalado en el considerando anterior, la Constitución exige que las sentencias tengan fundamentos. Sin embargo, corresponde al legislador establecer la forma en que debe hacerse dicha fundamentación. En efecto, corresponde al legislador establecer siempre las garantías de un procedimiento racional y justo, según el artículo 19 No 3 . Además, el artículo 63 No $3^{\circ}$ dispone que son materia de ley aquellas que son objeto de codificación procesal u otra. En cualquier caso, el legislador, al establecer cómo se debe hacer la fundamentación de las sentencias, debe respetar la esencia del derecho a un debido proceso (artículo 19 No 26).

5. Que, en consecuencia, la exigencia de fundamentación no implica que todas las sentencias deben tener un exhaustivo y completo análisis de los antecedentes. Ello va en relación a la naturaleza de los procedimientos. Tratándose de procedimientos orales y concentrados, basta que exista un razonamiento, aunque sea mínimo y entendible, de la forma en que el juez respectivo alcanzó el grado de convicción que la ley exige y consideró las alegaciones de las partes. Sobre todo si se establece la obligación de dictar sentencia al término de la audiencia.

Ello se cumple con la exigencia de "consideraciones jurídicas", que contempla el artículo $459 \mathrm{~N}^{\circ} 6$ del Código del Trabajo, sin que ello implique hacer equivalente esta exigencia con la de analizar toda la prueba.

6. Que la vinculación entre el respeto que debe existir de los derechos y garantías constitucionales y la sentencia en un juicio laboral, se expresa en la existencia de un recurso 
de nulidad. Dicho recurso, plenamente procedente en el procedimiento monitorio, por mandato del artículo 502 del Código del Trabajo, procede por causales específicas que regula el artículo 478 de dicho Código y por una causal genérica, establecida en el artículo 477 .

7. Que, dado que el artículo 501 exime al juez laboral de cumplir con el análisis de la prueba, no procede dicho recurso por la causal específica señalada en la letra b) del artículo 478 , es decir, cuando la sentencia "haya sido pronunciada con infracción manifiesta de las normas sobre la apreciación de la prueba conforme a las reglas de la sana crítica". Pero sí procede por la causal genérica del artículo 477, esto es, "cuando en la tramitación del procedimiento o en la dictación de la sentencia definitiva se hubieren infringido sustancialmente derechos o garantías constitucionales", toda vez que la ausencia completa de consideraciones jurídicas en la sentencia afecta el derecho establecido en el $19 \mathrm{~N}^{\circ} 3$ de la Constitución y las garantías señaladas en los artículos $4^{\circ}$ y $8^{\circ}$ de la misma Carta Fundamental.

8. Que, siendo procedente el recurso de nulidad por la causal señalada, a estos previnientes les resulta claro que no se pone en entredicho el derecho a un procedimiento justo con lo establecido en el inciso final del artículo 501 del Código del Trabajo, pues el tribunal competente puede siempre juzgar si en la sentencia de primer grado existe correspondencia entre la prueba considerada y la resolución que se dictó. Precisamente, de acuerdo con el artículo 54 del Decreto Supremo No 3, de 1984, del Ministerio de Salud, que estableció el Reglamento de Autorización de Licencias Médicas por las COMPIN e Instituciones de Salud Previsional, puede admitirse una licencia médica, después de los dos días hábiles de iniciada, siempre que se presente dentro del período de duración de la licencia y que el retardo se haya debido a un caso fortuito o fuerza mayor. Además de la consideración de los días hábiles para su presentación. Entonces, a juicio de estos previnientes, es posible analizar el recurso de nulidad examinando si efectivamente la presentación de la licencia médica, que es el objeto principal de la gestión pendiente, ha sido oportuna o no.

9. Que, en consecuencia, a juicio de estos previnientes, la aplicación del precepto legal impugnado no resulta contraria a la Constitución.

Redactó la sentencia el Ministro señor Hernán Vodanovic Schnake. La primera prevención fue redactada por el Ministro señor Marcelo Venegas Palacios

(Presidente) y la segunda, por sus autores. Notifíquese, regístrese y archívese.

Se certifica que los Ministros señores Raúl Bertelsen Repetto y José Antonio VieraGallo Quesney concurrieron a la vista de esta causa y al fallo, pero no firman por encontrarse con permiso. Pronunciada por el Excmo. Tribunal Constitucional, integrado por los Ministros señores Marcelo Venegas Palacios (Presidente), Raúl Bertelsen Repetto, Hernán Vodanovic Schnake, señora Marisol Peña Torres y señores Enrique Navarro Beltrán, Francisco Fernández Fredes, Carlos Carmona Santander, José Antonio Viera-Gallo Quesney e Iván Aróstica Maldonado.

Autoriza el Secretario (S) del Tribunal Constitucional, Jaime Silva Mac Iver. 